\title{
Resistance of rocky shore assemblages of algae and invertebrates to changes in intensity and temporal variability of aerial exposure
}

\author{
Iacopo Bertocci ${ }^{1,2, *}$, Elena Maggi ${ }^{1}$, Stefano Vaselli ${ }^{1}$, Lisandro Benedetti-Cecchi ${ }^{1}$ \\ ${ }^{1}$ Dipartimento di Biologia, University of Pisa, CoNISMa, Via Derna 1, 56126 Pisa, Italy \\ ${ }^{2}$ Present address: CIIMAR (Centro Interdisciplinar de Investigação Marinha \& Ambiental), Rua dos Bragas 289, \\ 4050-123 Porto, Portugal
}

\begin{abstract}
Experimental investigations of biological responses to changes in mean intensity and temporal variability of environmental conditions are key to anticipating effects of predicted climate change. We examined the ability of rocky shore organisms to resist increased levels of aerial exposure due to prolonged periods of high barometric pressure and calm sea conditions. By temporarily transplanting assemblages from the lowshore environment to mid- and high-shore habitats and varying the temporal intervals between successive transplantations, we examined the effects of intensity and temporal variability of aerial exposure. Resistance was evaluated through comparisons of multivariate and univariate response variables between transplanted cores and reference assemblages in the lowshore habitat. When differences emerged from these comparisons, we hypothesized that assemblages could shift towards those occurring under natural conditions of more severe aerial exposure. This was tested by comparing transplanted assemblages to those occurring naturally higher on the shore. The study was repeated twice to test for the generality of outcomes. Although individual taxa showed mixed responses varying between experimental trials that in some cases made their abundances similar to those occurring higher on the shore, whole assemblages and the number of taxa did not generally respond to experimental treatments. Present findings add to the few experimental investigations of the interactive effects of mean intensity and temporal variance of climatic variables, contributing to refined predictions of responses of rocky shore organisms to climate change.
\end{abstract}

KEY WORDS: Aerial exposure - Climate change · Disturbance · Environmental fluctuations · Resistance $\cdot$ Rocky shore $\cdot$ Mediterranean Sea

\section{INTRODUCTION}

Intertidal organisms are exposed to large fluctuations in climate variables (Hawkins \& Jones 1992, Raffaelli \& Hawkins 1996). Desiccation, thermal fluctuations and enhanced irradiation due to aerial exposure are among the main drivers of spatial and temporal changes in patterns of distribution, abundance and diversity of assemblages (Dayton 1971, Schonbeck \& Norton 1978, Denny 1988, Davison et al. 1993, Bertness \& Leonard 1997, Bertness et al. 1999, MolinaMontenegro et al. 2005). Climate events such as global warming, storminess and precipitation can drastically modulate the effects of these abiotic factors (Navarrete et al. 1993, Barry et al. 1995, Sanford 1999, Hughes 2000). The influence of these factors on intertidal assemblages is expected to increase in the near future according to the environmental scenarios predicted by several models of climate change. In particular, there are indications that the frequency, intensity and variability of extreme events such as storms (Emanuel 1987, Raper 1993, Michener et al. 1997, Muller \& Stone 2001), droughts and floods (Easterling et al. 2000a,b) will increase as a consequence of climate change. 
Unlike marine basins where regular patterns of submersion and emersion are an intrinsic feature of intertidal habitats due to tidal cycles (Menge \& Branch 2001), in atidal systems, such as the NW Mediterranean Sea (Menconi et al. 1999), the Baltic Sea (Alhonen 1966) and the Swedish west coast (Johannesson 1989), events of aerial exposure are more tightly related to weather conditions, including atmospheric pressure, wind direction and wave exposure. Sessile organisms are exposed to air during prolonged periods of calm sea, generally corresponding to high barometric pressure, while waves may reduce the desiccation of substratum at relatively high levels on the shore. Changes in intensity and temporal patterns of prevalent weather conditions may affect intertidal assemblages on rocky shores through a variety of direct and indirect mechanisms (e.g. Bertocci et al. 2007). Diversity of assemblages and percentage covers of organisms, such as filamentous and coarsely branched algae, were reduced by events of prolonged aerial exposure regularly distributed through time, while opposite responses were documented under greater temporal variability of events of comparable intensity (BenedettiCecchi et al. 2006). Increasing temporal variability of prolonged aerial exposure also enhanced or dampened temporal fluctuations in the abundance of different organisms, depending on taxon-specific characteristics in terms of the ability to resist to and/or to recover from aerial exposure (Bertocci et al. 2007). To what extent lowshore assemblages are resistant to simultaneous changes in the intensity and temporal variability of aerial exposure and which combinations of such factors can make these assemblages more similar to those occurring naturally under more severe environmental conditions still need to be addressed. Addressing such issues is of fundamental importance to anticipate responses of intertidal assemblages to climate change.

In the present study, transplantations of assemblages from lowshore habitats to higher heights on the shore (midshore and highshore levels) were used to manipulate indirectly the intensity of aerial exposure. Assemblages were left in the new position for some time and then returned to their original position. We manipulated temporal variability of aerial exposure by transplanting organisms either at regular or at variable intervals of time. This experimental design allowed us to examine the separate and interactive effects due to changes in intensity and temporal variability of aerial exposure, as described in detail in previous papers (Benedetti-Cecchi 2003, Benedetti-Cecchi et al. 2006, Bertocci et al. 2007). Here, the transplanted assemblages were compared with natural ones in the lowshore habitat, allowing us to examine the resistance of organisms to different regimes of aerial exposure. Resistance was defined here as the ability of assem- blages to remain essentially unchanged despite the occurrence of disturbance (see Grimm \& Wissel 1997 for an exhaustive inventory and discussion of definitions). Moreover, comparisons between transplanted assemblages and those occurring naturally in midshore and highshore habitats, enabled us to examine which traits of aerial exposure, if any, contributed to shaping assemblages moved experimentally to different heights on the shore. The largest differences were predicted between unmanipulated lowshore assemblages and assemblages transplanted to the highshore habitat, particularly when this treatment was applied under high temporal variability. Such a combination of experimental factors, in fact, implied the occurrence of more prolonged periods of aerial exposure compared to other treatments, which should result in the most stressing environmental conditions. At individual taxon level, taxa that are naturally most common in the lowshore habitat and relatively rare higher on the shore were those expected to display greater shifts in abundance when disturbed. We also predicted that the same taxa could more easily converge to the abundance values currently measured higher on the shore. The study was repeated twice, using similar procedures, to examine the generality of the effects investigated.

\section{MATERIALS AND METHODS}

Experimental design. Each experimental trial (hereafter indicated as Expt 1 and Expt 2, respectively) was carried out on a stretch of coast 30 to $40 \mathrm{~m}$ in length along the rocky shore of Calafuria in the NW Mediterranean. Expt 1 started in July 2001, and Expt 2 in May 2002, at a site about $1000 \mathrm{~m}$ distant, and both lasted 2 yr. The study location, organisms, experimental procedures and treatments were the same used in our previous studies and they have been described in detail in other papers (Benedetti-Cecchi et al. 2006, Bertocci et al. 2007). Briefly, 8 cores (10 cm in diameter) with intact assemblages on top, were drilled at the lowshore level (corresponding to the Mean Low Water Level, MLWL) in each site and assigned to each of the following treatments: (1) Disturbed (D: cores drilled out and then placed back into the same position in the lowshore habitat, (2) Translocated (T: cores swapped horizontally within the lowshore habitat), (3) Midshore (cores transplanted from the lowshore habitat to $15-20 \mathrm{~cm}$ above MLWL) and (4) Highshore (cores transplanted from the lowshore habitat to $25-30 \mathrm{~cm}$ above MLWL). Treatment D was included to control for potential artefacts associated with drilling, manipulating and reattaching cores, whilst treatment $\mathrm{T}$ controlled for moving cores from one place to another independently of 
changes in height (Chapman 1986). Transplantations at increasing heights on the shore were used to manipulate the intensity of aerial exposure (low, LI, for midshore and high, HI, for highshore transplantations, respectively). Within each treatment, 4 cores were moved at near-regular intervals (low variability: LV) over the course of the experiment, while the other 4 cores were manipulated at variable intervals of time (high variability: HV). The total duration of permanence higher on the shore was the same $(9 \mathrm{mo})$ for LV and HV treatments, so our experimental design allowed us to tease apart the effects of the overall intensity from those of the temporal variability of disturbance (Benedetti-Cecchi 2003). A diagrammatic representation of experimental treatments is illustrated in Fig. S1 (Supplement 1, available at www.intres.com/articles/suppl/m400p075_app.pdf).

Six (Expt 1) and 5 (Expt 2) dates of sampling were distributed over the course of the study. At each date, in addition to sampling assemblages on each core (4 replicates for each combination of experimental factors) following the procedures described in previous papers (Benedetti-Cecchi et al. 2006, Bertocci et al. 2007), we sampled visually (Dethier et al. 1993) the unmanipulated assemblages occurring at lowshore (40 plots), midshore (8 plots) and highshore (8 plots) levels. Both the manipulated and unmanipulated units were sampled with quadrats of $8 \times 8 \mathrm{~cm}$, which were appropriate given the small size of the organisms involved. The abundance of each taxon was expressed as percentage cover (sessile organisms) or number of individuals (mobile animals) in each quadrat. The unmanipulated assemblages sampled in the lowshore habitat and at each of the other heights on the shore were used as reference to quantify the resistance and the degree of convergence of manipulated assemblages towards those of the destination habitat under the different disturbance regimes, respectively.

Two sites were established for Expt 1, but most cores disappeared from one site due to a heavy storm early in the experiment, so data from that site are not reported. Only one site could be established for Expt 2 due to logistical constraints. Hence, any difference in outcomes between trials cannot be unequivocally ascribed to spatial or temporal sources of variability, with one site per trial.

Analysis of data. Resistance of assemblages to disturbance was quantified by comparing manipulated assemblages with natural ones. For this purpose, each core was paired with an unmanipulated plot in the lowshore habitat before analysis. Comparisons were based on average responses over the entire study period. Such an approach was chosen for 2 reasons. First, the hypotheses investigated concerned the whole duration of the study and not the individual dates of sampling (for which the concept of variance is meaningless). Second, at any date of sampling the time interval between that date and that of the previous manipulation differed among variance treatments. Thus, analyses conducted at single dates of sampling would have confounded aerial exposure with the time elapsed since the last manipulation (see also BenedettiCecchi et al. 2006, Bertocci et al. 2007). Comparisons were therefore based on centroids describing the average assemblage of each core or the unmanipulated condition over the course of the study. Because the average of raw abundance data of individual taxa is not an appropriate measure of average assemblages across time (Legendre \& Anderson 1999, McArdle \& Anderson 2001), a principal coordinate analysis (Gower 1966) was applied to the Bray-Curtis (Bray \& Curtis 1957) matrix of dissimilarities, using the programme PCO (Anderson 2003). From this analysis we extracted the pairwise differences between average manipulated and unmanipulated assemblages, expressed as Euclidean distances.

Euclidean distances were compared among treatments with analysis of variance (ANOVA). Due to the complexity of the design, we separated analyses aimed at testing for artefacts (those involving treatments D and $\mathrm{T}$ ) from those examining the effects of intensity and temporal variability of disturbance. Artefacts were examined with a 1-way ANOVA with 5 levels: DLV, DHV, TLV, THV and RL, indicating disturbed cores at low and high variability, translocated cores at low and high variability and reference assemblages in the lowshore habitat, respectively. Effects of the regime of disturbance were examined with a 2-way ANOVA including the crossed factors Intensity (LI vs. HI) and Variability (LV vs. HV). In the case of significant results, showing a departure of manipulated assemblages from those occurring naturally in the lowshore habitat, a 2-way ANOVA was done to compare the effects of intensity and temporal variability of aerial exposure on the Euclidean distances measuring the differences between manipulated assemblages and the assemblages occurring naturally in the destination habitat. In this case distances were obtained by pairing the 4 cores assigned to each combination of height of transplantation and temporal variability with the unmanipulated plots sampled in the midshore and highshore habitats.

Data on mean abundances of common taxa and total number of taxa (a surrogate measure for species diversity) across the study period were analysed with 1-way ANOVAs to evaluate responses of different organisms and changes in diversity induced by experimental treatments. Various analyses were conducted to test for the occurrence of artefacts, resistance to disturbance and convergence of response variables towards 
values observed in the destination habitat. The analysis of artefacts compared the same experimental levels as those included in the multivariate analysis. Treatment effects on resistance to aerial exposure were examined by contrasting 5 treatments: low intensity treatments at low and high variability, high intensity treatments at low and high variability and reference plots sampled in the lowshore habitat (abbreviated as LILV, LIHV, HILV, HIHV and RL, respectively). Effects of treatments on shifts of response variables towards values occurring higher on the shore were examined by comparing separately for each habitat (1) low intensity treatments at low and high variability and reference plots sampled in the midshore habitat (3 levels: LILV, LIHV and RM, respectively) and (2) high intensity treatments at low and high variability and reference plots sampled in the highshore habitat (HILV, HIHV and $\mathrm{RH}$, respectively).

Before each analysis, the assumption of homogeneity of variance was assessed using Cochran's $C$-test and data were $\ln (x+1)$-transformed when necessary (Underwood 1997). Student-Newman-Keuls (SNK) tests were used for a posteriori comparisons of means.

Only the most abundant and common taxa during each experimental trial were analysed, thus only a few taxa were included in the analyses of both Expt 1 and Expt 2.

Before any hypothesis about the effects of intensity and temporal variability of aerial exposure on assemblages could be advanced, it was necessary to ascertain whether assemblages really differed among heights on the shore. Temporally independent samples collected at each height allowed us to examine the effects of Habitat (fixed, 3 levels: lowshore, midshore and highshore), Time (random, 6 or 5 levels correspond- ing to the dates of sampling of Expt 1 and Expt 2, respectively) and their interaction, with a 2-way PERMANOVA (Anderson 2001), based on Bray-Curtis untransformed dissimilarities. Sample size consisted of 8 (Expt 1) or 7 (Expt 2) replicates for each combination of factors. Student's $t$-tests were used for a posteriori comparisons in case of significant results.

\section{RESULTS}

\section{Comparisons among reference assemblages}

Differences among assemblages naturally occurring at different heights on the shore varied between Expt 1 and Expt 2. In Expt 1, RL and RH assemblages differed throughout the study, while RM assemblages generally resembled either $\mathrm{RL}$ or $\mathrm{RH}$, depending on the date of sampling (Table 1). In Expt 2, the 3 reference assemblages differed from each other consistently throughout the period of study (Table 1).

Filamentous algae and encrusting corallines were generally the most abundant taxa in the lowshore habitat and became less abundant at increasing heights on the shore, whereas the barnacle Chthamalus stellatus and the cyanobacteria of the genus Rivularia displayed the opposite pattern becoming dominant in the highshore habitat. The lowshore habitat was also characterized by undetermined coarsely branched algae in Expt 1 and by Chondria boryana and Laurencia obtusa in Expt 2, while the midshore habitat was characterized by the encrusting brown alga Ralfsia verrucosa in Expt 1, but with cover values always below $10 \%$. The described patterns are illustrated in detail in Figs. 2 \& 3.

Table 1. PERMANOVA examining differences among reference assemblages in low- (RL), mid- (RM) and highshore (RH) habitat through the study period in each experiment. $\mathrm{T}_{1}$ to $\mathrm{T}_{6}$ (Expt 1) or $\mathrm{T}_{5}$ (Expt 2): sampling dates

\begin{tabular}{|c|c|c|c|c|c|c|}
\hline Source & $\mathrm{df}$ & MS & Pseudo- $F$ & $\mathrm{p}$ & Denominator & No. perm. units \\
\hline \multicolumn{7}{|l|}{ Expt 1} \\
\hline Habitat $(\mathrm{H})$ & 2 & 44365.0 & 21.69 & 0.001 & Residual & 144 \\
\hline Time (T) & 5 & 4814.5 & 2.35 & 0.001 & Residual & 144 \\
\hline $\mathrm{H} \times \mathrm{T}$ & 10 & 3442.4 & 1.68 & 0.003 & Residual & 144 \\
\hline Residual & 126 & 2045.3 & & & & \\
\hline $\begin{array}{l}\text { A posteriori } t \text {-tests } \\
\mathrm{H} \times \mathrm{T} \text { : }\end{array}$ & $\begin{array}{c}\mathrm{T}_{1} \\
\mathrm{RL} \neq \mathrm{RM}=\mathrm{RH}\end{array}$ & $\begin{array}{c}\mathrm{T}_{2} \\
\mathrm{RL} \neq \mathrm{RM}=\mathrm{RH}\end{array}$ & $\begin{array}{c}\mathrm{T}_{3} \\
\mathrm{RL}=\mathrm{RM} \neq \mathrm{RH}\end{array}$ & $\begin{array}{c}\mathrm{T}_{4} \\
\mathrm{RL} \neq \mathrm{RM}=\mathrm{RH}\end{array}$ & $\begin{array}{c}\mathrm{T}_{5} \\
\mathrm{RL} \neq \mathrm{RM}=\mathrm{RH}\end{array}$ & $\begin{array}{c}\mathrm{T}_{6} \\
\mathrm{RL} \neq \mathrm{RM} \neq \mathrm{RH}\end{array}$ \\
\hline \multicolumn{7}{|l|}{ Expt 2} \\
\hline Habitat (H) & 2 & 51876.0 & 30.27 & 0.001 & Residual & 105 \\
\hline Time $(\mathrm{T})$ & 4 & 4815.9 & 2.81 & 0.001 & Residual & 105 \\
\hline $\mathrm{H} \times \mathrm{T}$ & 8 & 2692.1 & 1.57 & 0.020 & Residual & 105 \\
\hline Residual & 90 & 1714.0 & & & & \\
\hline $\begin{array}{l}\text { A posteriori } t \text {-tests } \\
\mathrm{H} \times \mathrm{T} \text { : }\end{array}$ & $\begin{array}{c}\mathrm{T}_{1} \\
\mathrm{RL} \neq \mathrm{RM} \neq \mathrm{RH}\end{array}$ & $\begin{array}{c}\mathrm{T}_{2} \\
\mathrm{RL} \neq \mathrm{RM} \neq \mathrm{R}\end{array}$ & $\mathrm{RL} \neq \mathrm{R}$ & $\Gamma_{3}=\mathrm{RH}$ & $\begin{array}{c}\mathrm{T}_{4} \\
\mathrm{RL} \neq \mathrm{RM} \neq \mathrm{RH}\end{array}$ & $\begin{array}{c}\mathrm{T}_{5} \\
\mathrm{RL} \neq \mathrm{RM} \neq \mathrm{RH}\end{array}$ \\
\hline
\end{tabular}




\section{Control for artefacts}

ANOVA on Euclidean distances did not show any significant difference among treatments DLV, DHV, TLV, THV and RL for both Expt 1 and Expt 2, indicating the absence of procedural artefacts on the structure of assemblages. Detailed results are reported in Figs. S2 \& S3 (Supplement 2, available at www.intres.com/articles/suppl/m400p075_app.pdf). A general lack of procedural artefacts was also detected at the univariate level, with only a few exceptions. These are illustrated in detail in Supplement 2.

\section{Comparisons between transplanted and reference assemblages}

No combinations of treatments determined differences in Euclidean distances calculated between transplanted assemblages and RL assemblages in Expt 1 (Table 2, Fig. 1A). In Expt 2, assemblages undergoing aerial exposure at regular intervals differed more from $\mathrm{RL}$ ones than those undergoing more variable regimes of aerial exposure, independently of intensity (Table 2, Fig. 1B).

Building on the results of previous analyses, Euclidean distances between transplanted assemblages and assemblages naturally occurring in the destination habitat were compared only for Expt 2. Although variances could not be stabilized in this case, mean Euclidean distance was significantly lower for assemblages transplanted to the midshore than for those transplanted to the highshore habitat, independently of temporal variability (Table 3, Fig. 1C). However, high variability of aerial exposure tended to make assemblages transplanted to the midshore habitat more similar to reference assemblages compared to low variability, while such a pattern was reversed for assemblages transplanted to the highshore habitat (Fig. 1C).

The abundance of filamentous algae and Ralfsia verrucosa in Expt 1 (Table 4, Fig. 2C) and of Laurencia obtusa (Table 4, Fig. 3C) and the mean number of taxa (Table 4, Fig. 3G) in Expt 2 equalled values measured in the midshore habitat in treatment LILV, but not in LIHV.

Abundances analogous to RM values occurred under both levels of temporal variability for Rivularia spp. in both trials (Figs. 2E \& 3E), the number of taxa in Expt 1 (Fig. 2H) and filamentous algae (Fig. 3A), encrusting coralline algae (Fig. 3B) and C. stellatus (Fig. 3F) in Expt 2. However, the percentage cover of encrusting corallines (Table 4, Fig. 2B), Chthalamus stellatus (Table 4, Fig. 2F) and the limpets Patella aspera and $P$. caerulea (Table 4, Fig. 2G) in Expt 1 and of Chondrya boryana in Expt 2 (Table 4, Fig. 3D) differed from
Table 2. ANOVA on Euclidean distances between transplanted assemblages and reference assemblages in the lowshore habitat

\begin{tabular}{|c|c|c|c|c|c|}
\hline Source & $\mathrm{df}$ & MS & $F$ & $\mathrm{p}$ & Denom. for $F$ \\
\hline \multicolumn{6}{|l|}{ Expt 1} \\
\hline Intensity (I) & 1 & 28.51 & 1.11 & $>0.3$ & Residual \\
\hline Variability (V) & 1 & 2.25 & 2.35 & $>0.7$ & Residual \\
\hline $\mathrm{I} \times \mathrm{V}$ & 1 & 3.98 & 1.68 & $>0.7$ & Residual \\
\hline Residual & 12 & 25.64 & & & \\
\hline Cochran's test: & \multicolumn{5}{|c|}{$C=0.543, \mathrm{p}>0.05$} \\
\hline Transformation: & \multicolumn{5}{|c|}{ None } \\
\hline \multicolumn{6}{|l|}{ Expt 2} \\
\hline Intensity (I) & 1 & 0.41 & 0.01 & $>0.9$ & Residual \\
\hline Variability (V) & 1 & 545.98 & 8.92 & $<0.05$ & Residual \\
\hline $\mathrm{I} \times \mathrm{V}$ & 1 & 6.26 & 0.10 & $>0.7$ & Residual \\
\hline Residual & $11^{\mathrm{a}}$ & 61.20 & & & \\
\hline Cochran's test: & \multicolumn{5}{|c|}{$C=0.584, \mathrm{p}>0.05$} \\
\hline Transformation: & \multicolumn{5}{|c|}{ None } \\
\hline
\end{tabular}

reference in both LILV and LIHV treatments. Detailed ANOVAs comparing individual abundances on transplanted cores and RM quadrats are reported in Tables S1 to S4 (Supplement 3, available at www.intres.com/articles/suppl/m400p075_app.pdf).

Similarly to what was observed for the midshore habitat, temporal variability also affected the extent to which univariate response variables tended to converge towards values observed naturally in the highshore habitat. Under treatment HIHV, but not HILV, no differences resulted from such a comparison for encrusting coralline algae in both Expt 1 and Expt 2 (Table 4, Figs. 2B \& 3B, respectively), limpets in Expt 1 (Table 4, Fig. 2G) and Chthalamus stellatus in Expt 2 (Table 4, Fig. 3F); while the reverse occurred for Laurencia obtusa and Chondrya boryana in Expt 2 (Table 4, Fig. 3C \& 3D, respectively). Abundances not significantly different from RH were measured under both levels of temporal variability for $R$. verrucosa in Expt 1 (Fig. 2C) and Rivularia spp. in both Expt 1 (Fig. 2E) and Expt 2 (Fig. 3E). In contrast, differences with $\mathrm{RH}$ abundance values were maintained under both regimes of aerial exposure by C. stellatus in Expt 1 (Table 4, Fig. 2F), filamentous algae in Expt 2 (Table 4, Fig. 3A) and the number of taxa in both trials (Table 4, Figs. 2H \& 3G). Detailed ANOVAs comparing individual abundances on transplanted cores and $\mathrm{RH}$ quadrats are reported in Supplement 3.

Comparisons between transplanted and RL assemblages showed significant differences for Patella aspera and $P$. caerulea in Expt 1. Limpets were reduced in all cores, independently of the treatment, compared to their natural abundance occurring in the lowshore 
Transplanted vs. RL assemblage

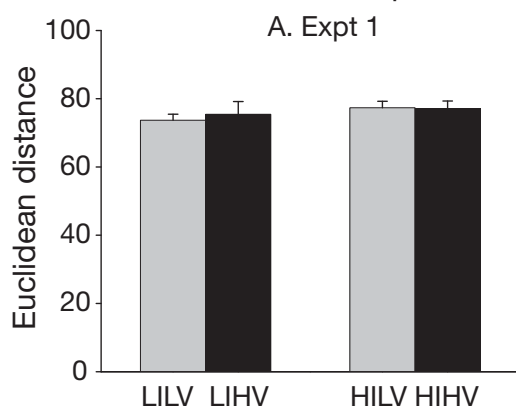

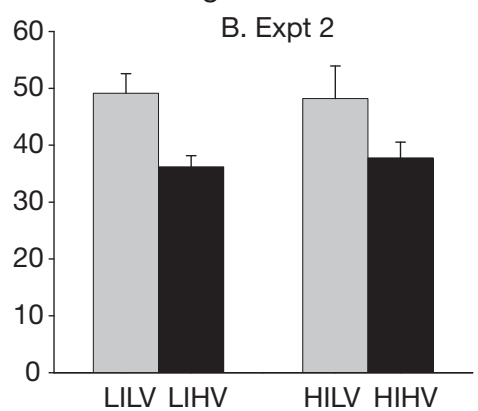

Transplanted vs. RM and $\mathrm{RH}$ assemblages

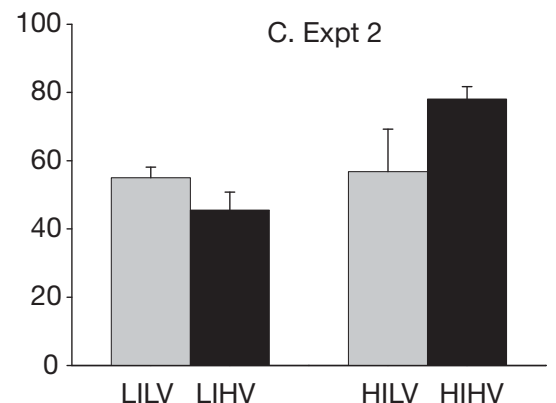

Fig. 1. Euclidean distances between $(\mathrm{A}, \mathrm{B})$ assemblages transplanted to the midshore habitat (low intensity exposure) under low and high variability (LILV and LIHV, respectively) or to the highshore habitat (high intensity exposure) under low and high variability (HILV and HIHV, respectively) and reference assemblages sampled in the lowshore habitat (RL) in Expt 1 and Expt 2; (C) transplanted assemblages (abbreviations as above) and reference assemblages sampled at midshore (RM) and highshore $(\mathrm{RH})$ level in Expt 2. Values are mean $+\mathrm{SE}, \mathrm{n}=4$

habitat (Fig. 2G, SNK: RL $>$ LIHV $=$ HILV $=\mathrm{HIHV}=$ LILV). In Expt 2, Laurencia obtusa (Fig. 3C) and Chondrya boryana (Fig. 3D) were drastically reduced in abundance under HILV treatment relatively to all other treatments, while their abundance increased markedly under high variability of transplantation both to the midshore and the highshore habitat (SNK: HIHV > HILV, no significant differences detected for other treatments). A similar pattern was displayed by filamentous algae in Expt 2 (Fig. 3A, SNK: HIHV > RH = LIHV = LILV = HILV) and, although not significant, in Expt 1 (Fig. 2A). Differences among treatments were not significant for all other taxa and for the total number of taxa either in Expt 1 or in Expt 2. Some trends, however, were evident from graphs. For example, encrusting corallines in both trials (Figs. 2B \& 3B) and Rivularia spp. in Expt 2 (Fig. 3E) decreased in abundance with increasing intensity and variability of aerial exposure, while an opposite pattern was observed for cyanobacteria in Expt 1 (Fig. 2E). The percentage cover of Ralfsia verrucosa in Expt 1 tended to be depressed in treatment LIHV compared to other conditions (Fig. 2C). The abundance of Chthalamus stellatus

Table 3. ANOVA on Euclidean distances between transplanted assemblages and reference assemblages in midshore or highshore habitat in Expt 2

\begin{tabular}{|lrrrrl|}
\hline Source & df & MS & $F$ & $p$ & Denom. for $F$ \\
\hline Intensity (I) & 1 & 1179.65 & 5.26 & $<0.05$ & Residual \\
Variability (V) & 1 & 139.19 & 0.62 & $>0.4$ & Residual \\
I $\times$ V & 1 & 946.69 & 4.22 & $>0.05$ & Residual \\
Residual & $11^{\mathrm{a}}$ & 224.19 & & & \\
Cochran's test: & $C=0.754, \mathrm{p}<0.05$ & \\
Transformation: & None \\
a Degrees of freedom corrected for missing data
\end{tabular}

was similar among experimental conditions in Expt 1 (Fig. 2F), whilst in Expt 2 this species transplanted to the midshore habitat tended to increase in abundance compared to RL condition, particularly under high variability (Fig. 3F). A further increase of barnacles was evident in HILV treatment, while in HIHV they were almost eliminated from the substratum. Detailed

Table 4. Summary of significant SNK tests on comparisons between the abundance of individual taxa and total number of taxa on transplanted cores and in reference quadrats. Abbreviations as in Fig. 1; Patella spp.: P. aspera, + P. caerulea

\begin{tabular}{|ll|}
\hline Taxon & Test summary \\
\hline Transplanted vs. RM & \\
Expt 1 & \\
Filamentous algae & LIHV $>$ LILV $=$ RM \\
Encrusting corallines & LIHV $=$ LILV $>$ RM \\
Ralfsia verrucosa & RM $=$ LILV $>$ LIHV \\
Chthamalus stellatus & RM $>$ LIHV $=$ LILV \\
Patella spp. & RM $>$ LIHV $=$ LILV \\
Expt 2 & \\
Laurencia obtusa & LIHV $>$ RM, no alternative \\
& hypothesis for LILV \\
Chondria boryana & LIHV $=$ LILV $>$ RM \\
Total no. of taxa & LIHV $>$ LILV $=$ RM \\
& \\
Transplanted vs. RH & \\
Expt 1 & \\
Encrusting corallines & HILV $>$ RH, no alternative \\
Chthamalus stellatus & hypothesis for HIHV \\
Patella spp. & HILV $>$ RH $=$ HIHV \\
Total no. of taxa & HILV $=$ HIHV $>$ RH \\
Expt 2 & \\
Filamentous algae & HIHV $>$ HILV $>$ RH \\
Encrusting corallines & HILV $>$ HIHV $=$ RH \\
Laurencia obtusa & HIHV $>$ HILV $=$ RH \\
Chondria boryana & HIHV $>$ HILV $=$ RH \\
Chthamalus stellatus & RH $=$ HILV $>$ HIHV \\
Total no. of taxa & HIHV $>$ HILV $>$ RH \\
\hline
\end{tabular}



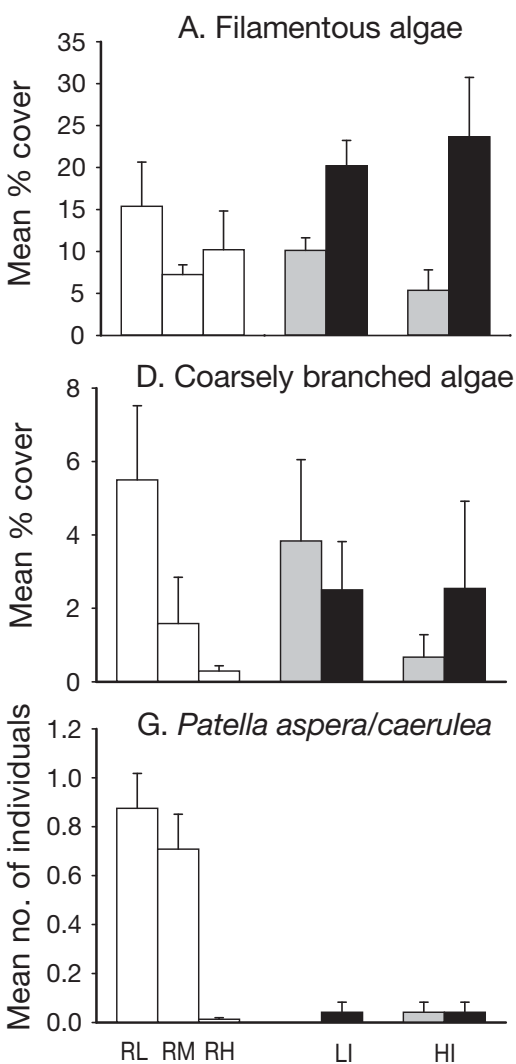

A. Filamentous algae
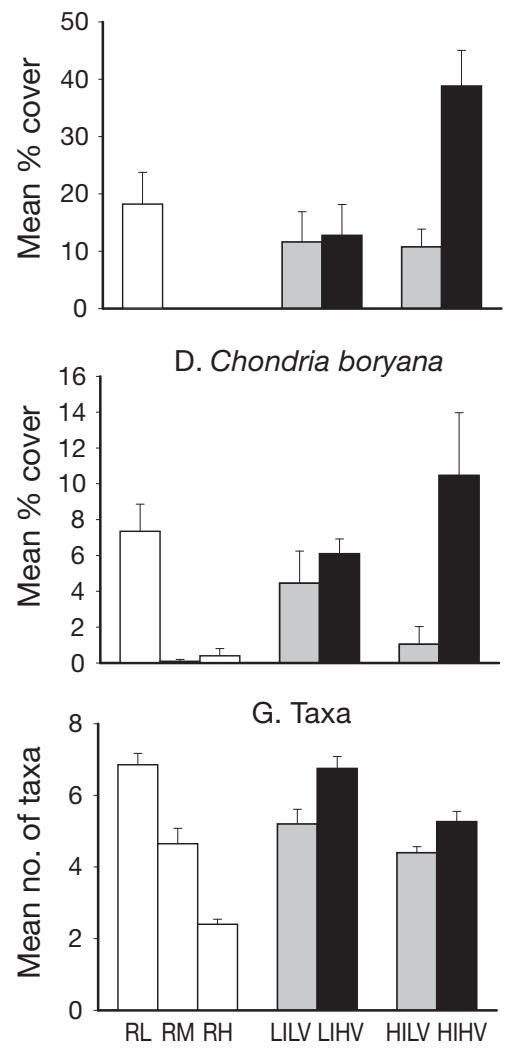

B. Encrusting coralline algae

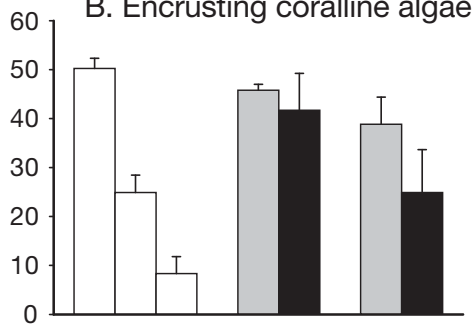

E. Rivularia spp.

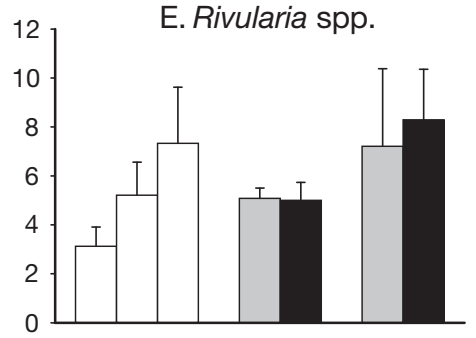

H. Taxa

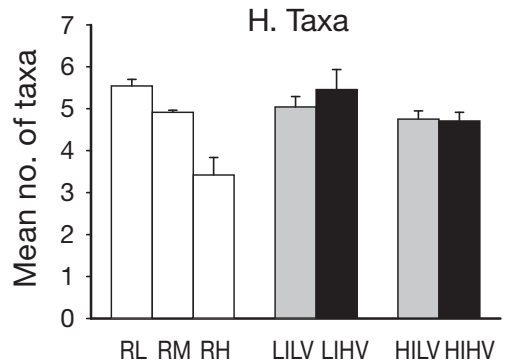

B. Encrusting coralline algae

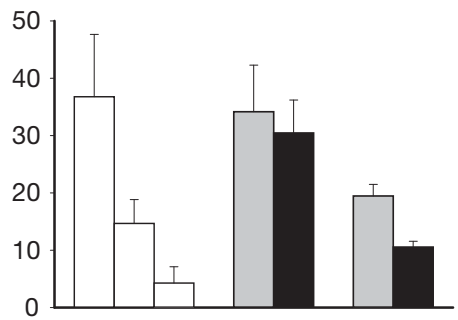

E. Rivularia spp.

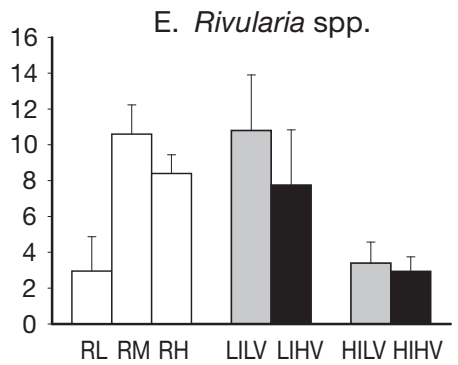

Fig. 3. Abundance of common taxa and total number of taxa on transplanted cores and in reference quadrats in Expt 2. Data are mean $+\mathrm{SE}(\mathrm{n}=4$ replicates per treatment; $\mathrm{RL}, \mathrm{n}=40$ quadrats; $\mathrm{RM}, \mathrm{RH}, \mathrm{n}=8$ quadrats). Abbreviations as in Fig. 1. Note that different panels have different scales 
ANOVAs comparing individual abundances on transplanted cores and RL quadrats are reported in Tables S5 \& S6 (Supplement 4, available at www.int-res.com/ articles/suppl/m400p075_app.pdf).

\section{DISCUSSION}

The present study indicated variable patterns of resistance of organisms to changes in intensity and temporal variability of aerial exposure. In Expt 1, manipulated and RL assemblages were similar in all treatments. In Expt 2, in contrast to expectations, low variability determined a larger differentiation between manipulated and RL assemblages compared to high variability, independently of the height of transplantation. Assemblages transplanted to the midshore habitat, however, tended to become more similar to reference assemblages compared to those transplanted to the highshore habitat.

Filamentous algae benefited from high variability, particularly when they were transplanted to the highshore habitat. These circumstances enhanced natural differences in the abundance of this taxon across heights. The abundance of encrusting corallines showed a gradual decline with increasing intensity and temporal variability of aerial exposure, becoming similar to that occurring naturally at that height of transplantation only in treatment HIHV in Expt 2. Increasing intensity of aerial exposure enhanced the abundance of cyanobacteria in Expt 1, while in Expt 2 this variable increased under low intensity and decreased under high intensity. Expt 1, treatments did not modify differences in the abundance of cyanobacteria occurring naturally at higher heights. In Expt 2, cover values of cyanobacteria transplanted to the midshore habitat were analogous to natural values at this height on the shore, while cores transplanted to the highshore habitat had 4 times less cyanobacteria than the RH condition. When cores were transplanted to the midshore habitat in Expt 2, the cover of barnacles increased, but it was still lower than in the RM condition. The abundance of barnacles increased with increasing intensity of aerial exposure, but only in treatments transplanted at regular intervals, where it matched that in the RH condition. With the exception of limpets, all other taxa showed comparable resistance to each treatment in Expt 1. In Expt 2, the abundance of Laurencia obtusa and Chondrya boryana decreased in HILV compared to other conditions, while L. obtusa benefited from treatment LIHV.

Increased percentage cover values of filamentous algae under the potentially most stressing experimental conditions might reflect indirect effects due to the concomitant reduction of grazers or competitors. Evi- dence in support of this interpretation was provided by the low abundance of limpets that characterized all treatments in Expt 1. Experimental removals of limpets have repeatedly shown that these grazers prevent the development of ephemeral algae (Underwood \& Jernakoff 1981, Farrell 1988, Hawkins et al. 1992, Bulleri et al. 2000, Benedetti-Cecchi et al. 2001). Filamentous algae may have also benefited from the slight reduction of encrusting coralline algae under increasing intensity and temporal variability of aerial exposure, although encrusting corallines were not indicated as strong competitors for space (Breitburg 1984). Epithallial sloughing could be responsible for negative effects of coralline algae on epiphyte organisms (Keats et al. 1993). It is worth noting, however, that in one experimental trial filamentous algae were more abundant on THV cores than under natural conditions, suggesting the potential occurrence of artefacts.

Although cyanobacteria appeared generally resistant to experimental treatments, consistently with the almost ubiquitous distribution of microbial biofilms in aquatic systems (Underwood 1984, Hill \& Hawkins 1991, Bustamante et al. 1995, Costerton et al. 1995), differences in macroalgal cover and in the intensity of grazing might have also played a role in determining the different responses of this taxon between the 2 experimental trials (Jenkins et al. 1999, Harley \& Helmuth 2003, Thompson et al. 2004, 2005). In particular, the slight increase in abundance of cyanobacteria on cores transplanted to higher heights on the shore in Expt 1 could be ascribed to their release from grazing by limpets, while in Expt 2, where limpets were naturally less abundant, the strength of negative effects could have been increased due to the greater abundance of filamentous and turf-forming algae, such as Laurencia obtusa and Chondrya boryana. These algae can grow fast and recover quickly after disturbance (Benedetti-Cecchi \& Cinelli 1994, Benedetti-Cecchi 2000) and therefore they possess the appropriate lifehistory traits that guarantee persistence in harsh physical conditions.

A previous investigation documented the sensitivity of encrusting corallines to high intensity and temporal variability of aerial exposure (Benedetti-Cecchi et al. 2006). In the present study we have shown that these algae were buffered against changes in abundance only under the less extreme experimental conditions. This likely highlighted limits in the ability of these algae to tolerate disturbances directly or indirectly related to aerial exposure, including sediment scour (Airoldi 2000) and overgrowth by other organisms, such as algal turfs (Wetherbee 1979, Underwood 1980, Steneck 1983, 1986). Although it is known that encrusting corallines can survive for relatively long periods under bleaching conditions due to the transloca- 
tion of nutrients and metabolites across the thallus (Bulleri 2006), this mechanism did not prevent changes in abundance under the most stressful experimental conditions.

Relatively lower recruitment and greater mortality have been indicated as causes of the scarcity of barnacles in the lowshore habitat (Benedetti-Cecchi et al. 1999, 2000, Benedetti-Cecchi 2000). In the present study we have shown that when transplanted higher on the shore, barnacle cover on experimental units converged towards values occurring naturally in the receiving habitat. These new results confirm the contrasting effect that variance of aerial exposure had when manipulated at high intensity, particularly in Expt 2 (Benedetti-Cecchi et al. 2006, Bertocci et al. 2007). The negative effect of high variability was likely due to large mortality of barnacles during the prolonged periods of submersion associated with this treatment. However, other factors must be invoked to explain differences between Expt 1 and Expt 2 observed in the present study. These might include, for instance, hydrodynamic differences, as small-scale variations in water circulation were shown to be responsible for changes in patterns of distribution of barnacle larvae, therefore accounting for the patchy distribution of adults on rocky shores (Gaines \& Roughgarden 1985, Roughgarden et al. 1988, Gaines \& Bertness 1992). Differences in the availability of larvae at the beginning of each study could also have played a role, as Expt 1 and Expt 2 started towards the end of and at the beginning of the recruitment period of barnacles, respectively (Benedetti-Cecchi et al. 2000).

Finally, it is worth noting that the effects of experimental transplantations could be due to the influence of the different biotic habitat to which assemblages were exposed, compared to the lowshore origin habitat, rather than to changes in physical conditions. This was not addressed explicitly in the present study, however preliminary findings from a different manipulative study involving the use of plastic roofs covering the cores suggested that physical factors were more important than biotic habitat in these experiments. Such an issue has been discussed in much more detail by Bertocci et al. (2007).

Our results indicated that assemblages were resistant to changes in the intensity and temporal variability of aerial exposure in terms of the number of taxa, a surrogate of species diversity. An analogous finding was reported by Kelaher et al. (2003) after reciprocal transplantations of sessile assemblages between different heights on the shore. This result might be explained assuming that experimental treatments determined the alternation of favourable and unfavourable environmental conditions for organisms with different life-histories, causing the mean number of taxa over the course of the study to remain relatively stable, contrarily to what was documented for the temporal variance (Bertocci et al. 2007). At the same time, only in a few cases did changes induced by particular treatments enhance (i.e. barnacles in treatment HILV in Expt 2) or decrease (i.e. encrusting corallines in treatment HILV and filamentous algae in LILV in Expt 1) abundances to natural values typical of higher heights on the shore.

At least 2 non-mutually exclusive interpretations can be suggested for the inconsistent results obtained in the 2 trials. First, a contribution could have been provided by the different temporal sequences of events of aerial exposure applied to generate the desired treatments in Expt 1 and Expt 2 (Gonzalez \& Holt 2002, Atalah et al. 2007). This issue could be addressed specifically by replicating random sequences of events within each level of temporal variance, i.e. different sequences generating the same value of variance of the intervals of time between successive disturbances (Vaselli et al. 2008). Second, although temporal and spatial variability could not be separated in this study, the documented differences were consistent with variable patterns of colonisation and distribution of sessile organisms between stretches of coast $100 \mathrm{~s}$ to $1000 \mathrm{~m}$ apart, apparently characterized by analogous abiotic conditions, reported previously at the same location (Benedetti-Cecchi \& Cinelli 1994) and in other systems (Foster 1990, Kennelly \& Underwood 1992). This could be due to local variations in the availability of larvae and propagules (Caffey 1985, Connell 1985, Gaines \& Roughgarden 1985, Roughgarden et al. 1988, Raimondi 1990) and in patterns of post-settlement mortality (Denley \& Underwood 1979), or to the patchy occupation of the substratum by adults of the same species (Sousa 1984). All these factors could also have differed between Expt 1 and Expt 2 as a function of their different starting dates. To formally investigate patterns of variability in space and time of responses of assemblages to aerial exposure would require the repetition of experiments at different sites and starting dates. Unfortunately, logistical and ethical difficulties intrinsic to the procedures adopted prevented us from carrying out replications of the experiments designed specifically to address the issues discussed above.

A main goal of this study was to improve our ability of predicting responses of rocky shore organisms to climate change. Our results indicated that some organisms can increase and others decrease in abundance under high temporal variability of aerial exposure, but these variations are not expected to produce changes to the structure of whole assemblages and to species diversity so profound as to cause them to shift towards those occurring currently under natural conditions of enhanced aerial exposure. Although the use in the 
future of implemented experimental designs, as discussed above, could refine our predictions, this is a new aspect of the ecology of these assemblages confirming that the majority of the investigated organisms possess the appropriate life-history traits to resist to changes in the mean intensity and temporal variability of disturbance (Benedetti-Cecchi et al. 2006, Bertocci et al. 2005, 2007). Nevertheless, it is worth noting that aerial exposure and desiccation may be important sources of stress in other systems characterized by species potentially more sensitive to fluctuations in climatic variables (Fields et al. 1993, Collins 2000, McCabe \& Gotelli 2000, Allison 2004). In our study system, however, further experimental investigations are needed to address possible responses of organisms to combined disturbances (Paine et al. 1998), such as those predicted by climate models.

Acknowledgements. We thank D. Balata and F. Bulleri for helpful comments on the manuscript and L. Di Giacomo, F. Lemmi, C. Rustighi and C. Valleggi for assistance in the field. The manuscript benefited from comments by E. Yakovis and 3 anonymous reviewers. This research is part of a PhD dissertation by I.B. at the University of Pisa and was in part supported by the CoML project NaGISA and the MarBEF Network of Excellence (EU Sixth Framework Programme, contract no. GOCE-CT-2003-505446). This is contribution number MPS_09039 of MarBEF.

\section{LITERATURE CITED}

Airoldi L (2000) Effects of disturbance, life histories, and overgrowth on coexistence of algal crusts and turfs. Ecology 81:798-814

Alhonen P (1966) Baltic Sea. In: Fairbridge RW (ed) The encyclopedia of oceanography. Van Nostrand Reinhold Company, New York, p 87-91

Allison G (2004) The influence of species diversity and stress intensity on community resistance and resilience. Ecol Monogr 74:117-134

Anderson MJ (2001) A new method for non-parametric multivariate analysis of variance. Austral Ecol 26:32-46

Anderson MJ (2003) PCO: a FORTRAN computer program for principal coordinate analysis. Department of Statistics, University of Auckland, www.stat.auckland.ac.nz/ mja/ prog/PCO_UserNotes.pdf

Atalah J, Otto SA, Anderson MJ, Costello MJ, Lenz M, Wahl M (2007) Temporal variance of disturbance did not affect diversity and structure of a marine fouling community in north-eastern New Zealand. Mar Biol 153:199-211

Barry JP, Baxter CH, Sagarin RD, Gilman SE (1995) Climaterelated, long-term faunal changes in a California rocky intertidal community. Science 267:672-675

Benedetti-Cecchi L (2000) Predicting direct and indirect interactions during succession in a midlittoral rocky shore assemblage. Ecol Monogr 70:45-72

Benedetti-Cecchi L (2003) The importance of the variance around the mean effect size of ecological processes. Ecology 84:2335-2346

Benedetti-Cecchi L, Cinelli F (1994) Recovery of patches in an assemblage of geniculate coralline algae: variability at different successional stages. Mar Ecol Prog Ser 110:9-18 Benedetti-Cecchi L, Menconi M, Cinelli F (1999) Pre-emption of the substratum and the maintenance of spatial pattern on a rocky shore in the northwest Mediterranean. Mar Ecol Prog Ser 181:13-23

Benedetti-Cecchi L, Acunto S, Bulleri F, Cinelli F (2000) Population ecology of the barnacle Chthamalus stellatus in the northwest Mediterranean. Mar Ecol Prog Ser 198: $157-170$

Benedetti-Cecchi L, Bulleri F, Acunto S, Cinelli F (2001) Scales of variation in the effects of limpets on rocky shores in the northwest Mediterranean. Mar Ecol Prog Ser 209: 131-141

Benedetti-Cecchi L, Bertocci I, Vaselli S, Maggi E (2006) Temporal variance reverses the impact of high mean intensity of stress in climate change experiments. Ecology 87: 2489-2499

Bertness MD, Leonard GH (1997) The role of positive interactions in communities: lessons from intertidal habitats. Ecology 78:1976-1989

> Bertness MD, Leonard GH, Levine JM, Bruno JF (1999) Climate-driven interactions among rocky intertidal organisms caught between a rock and a hot place. Oecologia 120:446-450

> Bertocci I, Maggi E, Vaselli S, Benedetti-Cecchi L (2005) Contrasting effects of mean intensity and temporal variation of disturbance on assemblages of rocky shores. Ecology 86: 2061-2067

Bertocci I, Vaselli S, Maggi E, Benedetti-Cecchi L (2007) Changes in temporal variance of rocky shore organism abundances in response to manipulation of mean intensity and temporal variability of aerial exposure. Mar Ecol Prog Ser 338:11-20

> Bray JR, Curtis JT (1957) An ordination of the upland forest communities of Southern Wisconsin. Ecol Monogr 27: 325-349

Breitburg DL (1984) Residual effects of grazing: inhibition of competitor recruitment by encrusting coralline algae. Ecology 65:1136-1143

Bulleri F (2006) Duration of overgrowth affects survival of encrusting coralline algae. Mar Ecol Prog Ser 321:79-85

Bulleri F, Menconi M, Cinelli F, Benedetti-Cecchi L (2000) Grazing by two species of limpets on artificial reefs in the northwest Mediterranean. J Exp Mar Biol Ecol 255:1-19

Bustamante RH, Branch GM, Eekhout S, Robertson B and others (1995) Gradients of intertidal primary productivity around the coast of South Africa and their relationships with consumer biomass. Oecologia 102:189-201

Caffey HM (1985) Spatial and temporal variation in settlement and recruitment of intertidal barnacles. Ecol Monogr 55:313-332

> Chapman MG (1986) Assessment of some controls in experimental transplants of intertidal gastropods. J Exp Mar Biol Ecol 103:181-201

> Collins SL (2000) Disturbance frequency and community stability in native tallgrass prairie. Am Nat 155:311-325

> Connell JH (1985) The consequences of variation in initial settlement vs. post-settlement mortality in rocky intertidal communities. J Exp Mar Biol Ecol 93:11-45

Costerton JW, Lewandowski Z, Caldwell DE, Korber DR, Lappin-Scott HM (1995) Microbial biofilms. Annu Rev Microbiol 49:711-745

> Davison IR, Johnson LE, Brawley SH (1993) Sublethal stress in the intertidal zone: tidal emersion inhibits photosynthesis and retards development in embryos of the brown alga Pelvetia fastigiata. Oecologia 96:483-492

Dayton PK (1971) Competition, disturbance, and community 
organization: the provision and subsequent utilization of space in a rocky intertidal community. Ecol Monogr 41: 351-389

> Denley EJ, Underwood AJ (1979) Experiments on factors influencing settlement, survival, and growth of two species of barnacles in New South Wales. J Exp Mar Biol Ecol 36:269-293

Denny MW (1988) Biology and the mechanics of the waveswept environment. Princeton University Press, Princeton, NJ

Dethier MN, Graham ES, Cohen S, Tear LM (1993) Visual versus random-point percent cover estimations: 'objective' is not always better. Mar Ecol Prog Ser 96:93-100

> Easterling DR, Evans JL, Groisman PY, Karl TR, Kunkel KE, Ambenje P (2000a) Observed variability and trends in extreme climate events: a brief review. Bull Am Meteorol Soc 81:417-425

Easterling DR, Meehl GA, Parmesan C, Changnon SA, Karl TR, Mearns LO (2000b) Climate extremes: observations, modeling, and impacts. Science 289:2068-2074

Emanuel KA (1987) The dependence of hurricane intensity on climate. Nature 326:483-485

> Farrell TM (1988) Community stability: effects of limpet removal and reintroduction in a rocky intertidal community. Oecologia 75:190-197

Fields PA, Graham JB, Rosenblatt RH, Somero GN (1993) Effects of expected global climate change on marine faunas. Trends Ecol Evol 8:361-367

Foster MS (1990) Organization of macroalgal assemblages in the Northeast Pacific: the assumption of homogeneity and the illusion of generality. Hydrobiologia 192:21-33

> Gaines SD, Bertness MD (1992) Dispersal of juveniles and variable recruitment in sessile marine species. Nature 360:579-580

Gaines S, Roughgarden J (1985) Larval settlement rate: a leading determinant of structure in an ecological community of the marine intertidal zone. Proc Natl Acad Sci USA 82:3707-3711

- Gonzalez A, Holt RD (2002) The inflationary effects of environmental fluctuations in source-sink systems. Proc Natl Acad Sci USA 99:14872-14877

Gower JC (1966) Some distance properties and latent root and vector method used in multivariate analysis. Biometrika 53:325-338

> Grimm V, Wissel C (1997) Babel, or the ecological stability discussion: an inventory and analysis of terminology and a guide for avoiding confusion. Oecologia 109:323-334

Harley CDG, Helmuth BST (2003) Local- and regional-scale effects of wave exposure, thermal stress, and absolute versus effective shore level on patterns of intertidal zonation. Limnol Oceanogr 48:1498-1508

Hawkins SJ, Jones DH (1992) Rocky shores. Immel Publishings, London

Hawkins SJ, Hartnoll RG, Kain JM, Norton TA (1992) Plant-animal interactions on hard substrata in the NorthEast Atlantic. In: John DM, Hawkins SJ, Price JH (eds) Plant-animal interactions in the marine benthos. The Systematics Association (Clarendon Press), Oxford, p 1-32

Hill AS, Hawkins SJ (1991) Seasonal and spatial variation of epilithic microalgal distribution and abundance and its ingestion by Patella vulgata on a moderately exposed rocky shore. J Mar Biol Assoc UK 71:403-423

- Hughes L (2000) Biological consequences of global warming: is the signal already apparent? Trends Ecol Evol 15:56-61

Jenkins SR, Hawkins SJ, Norton TA (1999) Direct and indirect effects of a macroalgal canopy and limpet grazing in structuring a sheltered inter-tidal community. Mar Ecol Prog
Ser 188:81-92

Johannesson K (1989) The bare zone of Swedish rocky shores: Why is it there? Oikos 54:77-86

Keats DW, Groener A, Chamberlain YM (1993) Cell sloughing in the littoral zone coralline alga, Spongites yendoi (Foslie) Chamberlain (Corallinales, Rhodophyta). Phycologia 32:143-150

Kelaher BP, Underwood AJ, Chapman MG (2003) Experimental transplantations of coralline algal turf to demonstrate causes of differences in macrofauna at different tidal heights. J Exp Mar Biol Ecol 282:23-41

Kennelly SJ, Underwood AJ (1992) Fluctuations in the distributions and abundances of species in sublittoral kelp forests in New South Wales. Austral Ecol 17:367-382

Legendre P, Anderson MJ (1999) Distance-based redundancy analysis: testing multispecies responses in multifactorial ecological experiments. Ecol Monogr 69:1-24

McArdle BH, Anderson MJ (2001) Fitting multivariate models to community data: a comment on distance-based redundancy analysis. Ecology 82:290-297

McCabe DJ, Gotelli NJ (2000) Effects of disturbance frequency, intensity, and area on assemblages of stream invertebrates. Oecologia 124:270-279

Menconi M, Benedetti-Cecchi L, Cinelli F (1999) Spatial and temporal variability in the distribution of algae and invertebrates on rocky shores in the northwest Mediterranean. J Exp Mar Biol Ecol 233:1-23

Menge BA, Branch GM (2001) Rocky intertidal communities. In: Bertness MD, Gaines SD, Hay ME (eds) Marine community ecology. Sinauer Associates, Sunderland, MA, p 221-252

Michener WK, Blood ER, Bildstein KL, Brinson MM, Gardner LR (1997) Climate change, hurricanes and tropical storms, and rising sea level in coastal wetlands. Ecol Appl 7: 770-801

> Molina-Montenegro MA, Muñoz AA, Badano EI, Morales BW, Fuentes KM, Cavieres LA (2005) Positive associations between macroalgal species in a rocky intertidal zone and their effects on the physiological performance of Ulva lactuca. Mar Ecol Prog Ser 292:173-180

Muller RA, Stone GW (2001) A climatology of tropical storm and hurricane strikes to enhance vulnerability prediction for the southeast U.S. coast. J Coast Res 17:949-956

Navarrete SA, Lubchenco J, Castilla JC (1993) Pacific Ocean coastal ecosystems and global climate change. Earth system responses to global change: contrast between north and South America. Academic Press, San Diego, CA

> Paine RT, Tegner MJ, Johnson EA (1998) Compounded perturbations yield ecological surprises. Ecosystems 1:535-545

Raffaelli DG, Hawkins SJ (1996) Intertidal ecology. Chapman \& Hall, London

Raimondi PT (1990) Patterns, mechanisms, consequences of variability in settlement and recruitment of an intertidal barnacle. Ecol Monogr 60:283-309

Raper SCB (1993) Observational data on the relationships between climatic change and the frequency and magnitude of severe tropical storms. In: Warrick RA, Barrow EM, Wigley TML (eds) Climate and sea level change: observations, projections and implications. Cambridge University Press, Cambridge, p 192-212

> Roughgarden J, Gaines SD, Possingham H (1988) Recruitment dynamics in complex life cycles. Science 241:1460-1466

> Sanford E (1999) Regulation of keystone predation by small changes in ocean temperature. Science 283:2095-2097

Schonbeck MW, Norton TA (1978) Factors controlling the upper limits of fucoid algae on the shore. J Exp Mar Biol Ecol 31:303-313 
Sousa WP (1984) Intertidal mosaics: patch size, propagule availability, and spatially variable patterns of succession. Ecology 65:1918-1935

Steneck RS (1983) Escalating herbivory and resulting adaptive trends in calcareous algal crusts. Paleobiology 9: 44-61

Steneck RS (1986) The ecology of coralline algal crusts: convergent patterns and adaptative strategies. Annu Rev Ecol Syst 17:273-303

Thompson RC, Norton TA, Hawkins SJ (2004) Physical stress and biological control regulate the producer-consumer balance in intertidal biofilms. Ecology 85:1372-1382

Thompson RC, Moschella PS, Jenkins SR, Norton TA, Hawkins SJ (2005) Differences in photosynthetic marine biofilms between sheltered and moderately exposed rocky shores. Mar Ecol Prog Ser 296:53-63

Underwood AJ (1980) The effects of grazing by gastropods and physical factors on the upper limits of distribution of

Editorial responsibility: Inna Sokolova,

Charlotte, North Carolina, USA intertidal macroalgae. Oecologia 46:201-213

Underwood AJ (1984) Vertical and seasonal patterns in competition for microalgae between intertidal gastropods. Oecologia 64:211-222

Underwood AJ (1997) Experiments in ecology. Their logical design and interpretation using analysis of variance. Cambridge University Press, Cambridge

Underwood AJ, Jernakoff P (1981) Effects of interactions between algae and grazing gastropods on the structure of a low-shore intertidal algal community. Oecologia 48: $221-233$

- Vaselli S, Bertocci I, Maggi E, Benedetti-Cecchi L (2008) Effects of mean intensity and temporal variance of sediment scouring events on assemblages of rocky shores. Mar Ecol Prog Ser 364:57-66

Wetherbee R (1979) Transfer connections: specialized pathways for nutrient translocation in a red alga? Nature 204: 858-859

Submitted: May 11, 2009; Accepted: November 13, 2009

Proofs received from author(s): February 2, 2010 